\section{Obstructive sleep apnoea and frequency of occupational injury}

Abstract We sought to determine whether patients with obstructive sleep apnoea (OSA) are at increased risk of occupational injury (OI). Patients referred to the University of British Columbia Hospital Sleep Laboratory for suspected OSA (May 2003 to July 2011 were recruited and rates and types of validated 0 I (that caused at least 1 day of disability) in the 5 years prior to polysomnography were calculated. In a sample of 1236 , patients with OSA were twice as likely $(O R=1.93,95 \% \mathrm{Cl}$ 1.06 to $3.50, p=0.03$ ) to suffer at least one Ol compared with patients without OSA. This association was attenuated $(\mathrm{OR}=1.76, \mathrm{Cl} 0.86$ to $3.59, p=0.12$ ) after controlling for

confounders. In a secondary analysis, patients with OSA were almost three times more likely $(\mathrm{OR}=2.88, \mathrm{Cl} 1.02$ to $8.08, \mathrm{p}=0.05)$ to suffer from an injury more likely related to reduced vigilance (eg, a fall or commercial motor vehicle crash) when compared with patients without OSA, and this again was attenuated after controlling for confounders $(\mathrm{OR}=2.42, \mathrm{Cl}$ 0.085 to $6.93, p=0.10$ ).

\section{INTRODUCTION}

Occupational injuries (OIs) are a major problem worldwide, resulting in an estimated 360000 fatal injuries per year; additionally, more than 960000 workers become injured daily because of OI. ${ }^{1}$ Obstructive sleep apnoea (OSA) results in sleep fragmentation, decreased alertness and neurocognitive dysfunction. ${ }^{2}{ }^{3} \mathrm{We}$ hypothesised that patients with OSA might have an increased risk of OI, particularly those injuries that might be related to reduced vigilance. To address this issue, we analysed a large cohort of patients using validated measures of OI and OSA.

\section{METHODS}

Consenting adult patients who reported working more than $10 \mathrm{~h}$ per week and were referred to the University of British Columbia Hospital Sleep Disorder Laboratory for polysomnography (PSG) for suspected OSA between January 2003 and July 2011 were eligible for recruitment. Patients were excluded if they were medically unstable, had a mental disability or had active psychiatric disease.

Inpatient PSG was performed using conventional instrumentation and scored according to standard recommendations. ${ }^{4}$ Patients were dichotomised as 'yes' or 'no' for OSA, based on an apnea-hypopnea index (AHI) of $\geq 5 / \mathrm{h}$.

OIs were identified from claims data from WorkSafeBC. WorkSafeBC is the sole provider of workers' compensation benefits in the province of British Columbia for almost all (93-94\%) of the labour force. We only analysed claims that resulted in at least 1 day of absence from work, as these disability claims include data on the date and type of injury. ${ }^{5}$

On the night of PSG, patients were given a questionnaire that was completed in the sleep laboratory, and included information about medical history, type of industry defined as blue-collar (primary resources, manufacturing, construction or transportation and warehousing industries) or white-collar (eg, financial services or sales), and alcohol use (yes or no to consumption at least once per month). Subjective sleepiness was measured by the Epworth Sleepiness Scale (ESS). Body mass index (BMI) was calculated from height and weight measurements taken while patients were wearing light clothing.

\section{Data analysis}

The number of OIs in the 5 years prior to the PSG was determined for each patient. Since only a small portion of patients had multiple injuries, a binary definition for outcome (ie, any OI or no OI) was used. Logistic regression analysis was used to model the odds of OI between the OSA versus no OSA groups. The final model was adjusted for gender, BMI, alcohol use, age and industry group.
In a secondary analysis, the OI group was further divided into at least one vigilance related injury. These were injuries which were more likely to be related to reduced vigilance according to previous literature on mechanisms/causes of injury. $^{67}$ These vigilance related injuries included falls, contact with heat or electricity, motor vehicle crashes and injuries related to slipping/tripping. Given three levels of outcomes (ie, vigilance related injury, non-vigilance related injury and no injury), we used multinomial logistic regression to model the association between the odds of injury and OSA.

Statistical analyses were conducted using SAS V.9.2 (SAS Institute, Cary, North Carolina, USA).

\section{RESULTS}

There were a total of 1236 patients included in the analysis (tables 1 and 2). A total of 152 claims were reported; 59 (39\%) were vigilance related and 93 (61\%) were non-vigilance related. Of the 111 patients with OI, 49 patients (44\%) had at least one vigilance related injury while 62 patients $(56 \%)$ had non-vigilance related injuries. Almost 10\% (9.9\%) of patients with OSA had an OI compared with $5.4 \%$ of those without OSA (unadjusted odds 1.93 (CI 1.06 to 3.50, $\mathrm{p}=0.03)$ ). This association was attenuated in the multivariable model $(\mathrm{OR}=1.76, \mathrm{CI}$ 0.86 to $3.59, \mathrm{p}=0.12$ ).

Patients with OSA had an almost threefold increase in the odds of a vigilance related injury $(\mathrm{OR}=2.88$, CI 1.02 to 8.08 ,

Table 1 Baseline characteristics of patients with and without OSA

\begin{tabular}{|c|c|c|c|c|}
\hline & All $(n=1236)$ & $\begin{array}{l}\text { No OSA } \\
(n=242)\end{array}$ & OSA $(n=994)$ & $\begin{array}{l}p \\
\text { Value }\end{array}$ \\
\hline \multicolumn{5}{|l|}{ Continuous variable* } \\
\hline Age (years) & $49(40,55)$ & $44(35,53)$ & $49(42,56)$ & $<0.01$ \\
\hline $\mathrm{AHI}$ & $15(7,30)$ & $2(1,4)$ & $20(12,35)$ & $<0.01$ \\
\hline ESS & $10(6,14)$ & $11(7,14)$ & $10(6,14)$ & 0.86 \\
\hline Time worked per week (h) & $40(37,50)$ & $40(37,50)$ & $40(37,50)$ & 0.67 \\
\hline $\mathrm{BMI}$ & $30(27,35)$ & $28(25,33)$ & $31(27,35)$ & $<0.01$ \\
\hline Mean claim cost & $2139(736,6513)$ & $1085(404,4622)$ & $2159(792,6513)$ & 0.21 \\
\hline \multicolumn{5}{|l|}{ Categorical variables } \\
\hline Gender (female) & $374(30.3 \%)$ & $93(38.4 \%)$ & $281(28.3 \%)$ & $<0.01$ \\
\hline Alcohol (yes) & $855(69.2 \%)$ & $182(75.2 \%)$ & $673(67.8 \%)$ & 0.03 \\
\hline Industry (blue-collar) & $346(28 \%)$ & $61(25.2 \%)$ & $285(28.7 \%)$ & 0.28 \\
\hline \multicolumn{5}{|l|}{ Occupational injuries } \\
\hline Patients with injuries & $111(8.98 \%)$ & $13(5.37 \%)$ & $98(9.86 \%)$ & 0.03 \\
\hline $\begin{array}{l}\text { Patients with vigilance related } \\
\text { injuries }\end{array}$ & $49(3.96 \%)$ & $4(1.65 \%)$ & $45(4.53 \%)$ & 0.04 \\
\hline $\begin{array}{l}\text { Patients with non-vigilance related } \\
\text { injuries }\end{array}$ & $62(5.02)$ & $9(3.72 \%)$ & $53(5.33 \%)$ & 0.30 \\
\hline
\end{tabular}


Table 2 Predictors of occupational injuries: results of logistic and multinomial logistic regressions

\begin{tabular}{llll}
\hline Model/variable & OR & $95 \% \mathrm{Cl}$ & $\mathrm{p} \mathrm{Value}$ \\
\hline $\begin{array}{l}\text { Primary analysis: any injuries } \\
\text { Unadjusted OSA }\end{array}$ & 1.93 & $(1.06$ to 3.50$)$ & 0.03 \\
Adjusted OSA & 1.76 & $(0.86$ to 3.59$)$ & 0.12 \\
Gender & 0.605 & $(0.32$ to 1.15$)$ & 0.13 \\
BMI & 1.03 & $(0.99$ to 1.06$)$ & 0.42 \\
Alcohol use & 0.80 & $(0.50$ to 1.30$)$ & 0.37 \\
Industry (blue-collar) & 5.50 & $(3.39$ to 8.75$)$ & $<0.01$ \\
Age & 0.93 & $(0.97$ to 1.02$)$ & 0.56 \\
Secondary analysis: vigilance related injuries & & 0.05 \\
Unadjusted OSA & 2.88 & $(1.02$ to 8.08$)$ & 0.10 \\
Adjusted OSA & 2.42 & $(0.85$ to 6.93$)$ & 0.57 \\
Gender & 0.80 & $(0.37$ to 1.73$)$ & 0.02 \\
BMI & 1.04 & $(1.01$ to 1.08$)$ &
\end{tabular}

$\mathrm{p}$ value $=0.05)$ compared with patients without OSA. Again, this association was attenuated after adjusting for confounders $(\mathrm{OR}=2.42$, CI 0.85 to $6.93, \mathrm{p}=0.10)$.

There was no consistent relationship between OI and OSA severity (OI in $9.06 \%$ of patients with severe OSA, $10.94 \%$ with moderate OSA and 9.59\% with mild OSA). Higher ESS scores were also not associated with OI $(p=0.54$ in the unadjusted model).

\section{DISCUSSION}

Our findings are consistent with previous research showing increased rates of $\mathrm{OI}$ in patients with OSA. ${ }^{7-10}$ The stronger relationship with vigilance related injury adds further plausibility to our findings. Our study had many strengths. First, we used the gold standard for OSA diagnosis (PSG) rather than sleep related symptoms or limited ambulatory testing. ${ }^{4}$ In addition, OIs were validated through a claims database rather than self-reports (which would be susceptible to recall bias).
Finally, our sample size was relatively large.

However, there were a number of study limitations. First, risk of OI was assessed retrospectively from patients seen in a sleep disorders clinic, rather than from a population-based sample. This may introduce bias in that work performance or injury may have been a factor contributing to referral. Second, not all OIs are reported or captured by the workers' compensation system; however, if underto suggest that this would have been differential by OSA status. Third, the ability to investigate the association between OSA and OI may have been diluted by a study sample that included patients referred to the clinic for non-respiratory sleep disorders (ie, insomnia, narcolepsy, depression). However, this is likely a minor concern since patients with predominately non-respiratory complaints are usually referred to psychiatrists associated with our sleep disorder clinic. Finally, reporting occurred, there is no evidence

\section{Key messages}

What is the key question?

- Do patients with obstructive sleep apnoea (OSA) suffer more occupational injuries (OIs) than controls?

What is the bottom line?

- Patients with OSA are more likely to suffer an OI in the 5 years prior to polysomnography, and the impact may be greater for vigilance related injuries.

\section{Why read on?}

- This study uses a large sample size and both objective measures for predictor and outcome variables to demonstrate the magnitude of the additional risk borne by patients with OSA.

several potentially confounding variables were not included in the analysis either because the data was not reliable or available; these included information about shift working, and sedative medications.

Patients with OSA are more likely to suffer an OI in the 5 years prior to PSG, and the impact may be greater for vigilance related injuries. Future research should focus on identifying a high-risk group of workers who might benefit from screening, diagnostic testing and consequent treatment for OSA.

\section{A J Hirsch Allen, ${ }^{1}$ Julie E Park, ${ }^{2}$ Patrick R Daniele, ${ }^{2}$ John Fleetham, ${ }^{1,3}$ C Frank Ryan, ${ }^{1,3}$ Najib T Ayas ${ }^{1,3,4}$}

${ }^{1}$ Department of Medicine, University British Columbia, Vancouver, British Columbia, Canada

${ }^{2}$ Providence Health Care Research Institute, Vancouver, British Columbia, Canada

${ }^{3}$ Sleep Disorders Program, University British Columbia Hospital, Vancouver, British Columbia, Canada

${ }^{4}$ Centre Clinical Epidemiology and Evaluation,

Vancouver Coastal Health Research Institute, and

Centre Health Evaluation Outcome Sciences, Vancouver,

British Columbia, Canada

Correspondence to Dr Najib Ayas University of British Columbia, Room 224, St. Paul's Hospital, 1080 Burrard Street, Vancouver, British Columbia, Canada V6Z 1Y6; nayas@providencehealth.bc.ca

Funding CIHR (Sleep Disordered Breathing Team Grant), VCHRI Scientist Award, BC Lung Association Operating Grant.

Disclaimer All inferences, opinions and conclusions drawn in this manuscript are those of the authors, and do not reflect the opinions or policies of the data steward(s).

\section{Competing interests None declared.}

\section{Patient consent Obtained.}

Ethics approval University of British Columbia Office of Research Services Clinical Research Ethics Board.

Provenance and peer review Not commissioned; externally peer reviewed.

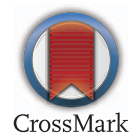

To cite Hirsch Allen AJ, Park JE, Daniele PR, et al. Thorax 2016;71:664-666.

Received 28 October 2015

Revised 17 February 2016

Accepted 18 February 2016

Published Online First 15 March 2016

Thorax 2016;71:664-666.

doi:10.1136/thoraxjnl-2015-207994

\section{REFERENCES}

1 Hämäläinen P, Leena Saarela K, Takala J. Global trend according to estimated number of occupational accidents and fatal work-related diseases at region and country level. J Saf Res 2009;40:125e39.

2 Gurubhagavatula I. Consequences of obstructive sleep apnoea. Indian J Med Res 2010;131:188-95.

3 Guglielmi O, Jurado-Gámez B, Gude F, et al. Occupational health of patients with obstructive sleep apnea syndrome: a systematic review. Sleep Breath 2015;19:35-44. 


\section{Research letter}

4 Berry RB, Budhiraja R, Gottlieb DJ, et al. Rules for scoring respiratory events in sleep: update of the 2007 AASM manual for the scoring of sleep andassociated events. Deliberations of the Sleep Apnea Definitions Task Forceof the American Academy of Sleep Medicine. J Clin Sleep Med 2012;8:597-619.

5 WorkSafeBC[creator]. WorkSafeBC Claims and Firm Level Files. Population Data BC[publisher]. Linked Dataset. WorkSafeBC. 2013. http://www.popdata.bc. ca/data
6 Kling RN, McLeod CB, Koehoorn M. Sleep Problems and Workplace Injuries in Canada. Sleep 2010;33:611-18.

7 Lindberg E, Carter N, Gislason T, et al. Role of snoring and daytimesleepiness in occupational accidents. Am J RespirCrit Care Med 2001;164:2031-5.

8 Uehli K, Mehta AJ, Miedinger D, et al. Sleep problems and work injuries:a systematic review and meta analysis. Sleep Med Rev 2014;18

61-73.
9 Ulfberg J, Carter N, Edling C. Sleep-disordered breathing and occupational accidents. Scand J Work Environ Health 2000;26:237-42.

10 Accattoli MP, Muzi G, dell'Omo M, et al. Occupational accidents, work performance and obstructive sleep apnea syndrome (OSAS). G Ital Med LavErgon 2008;30:297-303. 